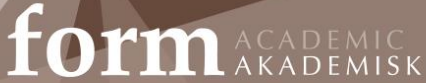

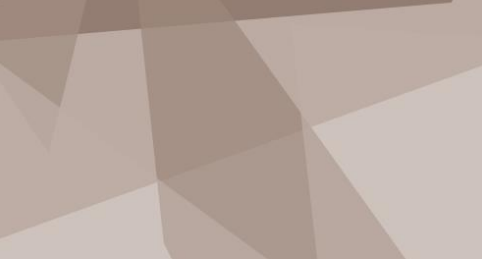

Vol I4, No 2 (2O2I)
Rebecca Gill

$\mathrm{PhD}$

University of Huddersfield

r.gill@hud.ac.uk

Claire Barber

PhD

University of Huddersfield

c.l.barber@hud.ac.uk

Bertrand Taithe

Professor

University of Manchester

bertrand.taithe@manchester.ac.uk

\title{
Humanitarian Handicrafts
}

\section{Testing the relationship between archival history and hands-on craft making}

\begin{abstract}
This paper asks how craft practice can inform historical reconsiderations of handicraft produced within a humanitarian socio-economic framework (to support humanitarian aims or fund-raising initiatives), and in turn explores how historical processes become materialised in contemporary humanitarian craftwork. By considering the possibilities for practice-based methods, this paper proposes the utility of involvement in craft-making processes for historians of humanitarianism. At the same time, this gives rise to a multiplicity of concerns for a contemporary craft practitioner undertaking a form of creative expression identifiable by its humanitarian purpose. It is therefore a helpful corrective to the temptation to think that experiments are innovations. Looking at early attempts in history we see a practice mirrored, not in the results, but in the process of working in a humanitarian mode of craft-based practice.
\end{abstract}

Keywords:

Interdisciplinary, embodied knowledge, humanitarianism, textiles

\section{AIM}

Our aim is to consider how craft practice can inform historical reconsiderations of humanitarian handicraft, and in turn to consider some of the ethical and artistic implications of how historical processes become materialised in contemporary humanitarian craftwork. The focus is a case study of 'Humanitarian Handicrafts: Materiality, Development and Fair Trade, A Re-evaluation', a workshop and 
participatory craft event which took place in June 2019 at the University of Huddersfield. It takes the form of a write-up of a round-table reflection which took place between the organisers following the event, including our discussion of the methods developed for the next iteration of the project. It thus represents an evolving discussion between the key collaborators. Here we review methods for sharing embodied knowledge and conceptual space in this collaboration between historians of humanitarianism and textile history, archivists, curators, contemporary craft practitioners, artists, and activists. In particular, we seek to interrogate the possibility of using craft to communicate across disciplinary convention. Our paper inquires into the role of imagination, affect and empathy; the positionality of the historian; the preservation of artistic and craft integrity; the potential for participatory methods in developing new historical questions; the ethical, artistic and political considerations for the conservation and display of humanitarian handicrafts; and the fostering of the necessary 'critical respect' (Malkki, 2015) for mutually productive engagement. Our paper thus operates as both example of and commentary upon the benefits and challenges of cross-disciplinary and interdisciplinary working between historians and craft practitioners.

\section{BACKGROUND AND SOURCES}

'Humanitarian Handicrafts: Materiality, Development and Fair Trade, A Re-evaluation' developed at the confluence of different tributaries, with a number of discussions and collaborations upstream of the event, and our multiple and varied historical and artistic references and experiences at their source. Claire Barber and her long-standing collaborator June Hill have worked together on a range of socially engaged textile projects, including The Sleeping Bag Project (2009-2013). This project brought new significance to discarded sleeping bags which remained after a music festival in Leeds, West Yorkshire. Volunteers, students and practitioners adapted the salvaged sleeping bags in order to withstand their reuse in a homeless shelter, as well as bringing an aesthetic quality and cultural value to the recovered items. In contemporary Britain, Barber and Hill have shown how such an everyday object as a sleeping bag can capture the imagination by creating a connection with participants, when they may not have been consciously seeking an insight separate from the functionality of this object. Nevertheless, an aesthetic gesture is surreptitiously tucked away. More recently Barber and Hill developed Blue Plaques of Intangible Experiences (2019) which used cloth to carry experiences of communities in Bradford. Bradford has been described as the archetypal post-industrial city. Tensions exist between different communities within this location; as counterpoint the engagement has drawn out the positives of living in a diverse community and individual perceptions of neighbourliness. Rebecca Gill, with her project partner Helen Dampier, works on the Emily Hobhouse Letters Project. This project explores the role of the Boer Home Industries textile schools in peace and reconstruction work following the South African War $(1899$ - 1902). Their research has uncovered the historical use of textile craft by international humanitarian groups who drew for inspiration upon the domestic craft-work of Quakers and Irish handicraft schemes. They have been particularly interested in how Boer women in South Africa operated as 'cultural entrepreneurs', taking up these schemes to negotiate questions of racial and class identity and create a Boer textile 'heritage' at a time of emerging Afrikaner nationalism. Bertrand Taithe has begun to explore the affinities of craft production and craft aesthetics in missionary and humanitarian work in the nineteenth and twentieth centuries. This includes the textiles sold by Huddersfield Famine Relief (Hudfam), which was an early affiliate of Oxfam, in the 1950s, and carpetmaking projects instigated by the Catholic White Fathers in North Africa and The Sahel.

First coming together as an informal discussion group, we realised that for historians the links between missionary craft projects and domestic social work initiatives in orphanages, asylums and workhouses is clear. Yet while the social circumstances for these domestic projects have been mapped, there remains relatively little historical work on overseas humanitarian or development craft projects, and in both cases very little engagement with material objects, their aesthetics, the embodied knowledge upon which they rely and generate, and their use and consumption. For the socially-engaged textile practitioner, meanwhile, such historical lineages are usually less obvious, and appear less relevant. In these discussions, we began to pinpoint certain traditions and practices in the past and 
present and make visible these connections. To explore these relationships further through a range of case studies, we organised a history workshop of papers and discussion interspersed with craftpractitioner demonstrations. This event took place in an exhibition space at the University of Huddersfield within which were displayed historical and contemporary humanitarian handicraft objects curated by Barber and Hill.

Our call for papers for this workshop advertised our intention to examine the circumstances in which humanitarians have sought to utilise arts and craft production variously as a means to engage disaffected humanitarian subjects, instil national values and aesthetics, create communities based on gender or nationality, 'transfer' skills or create cooperative forms of production. We also sought contributions from those interested in how this has fed into a culture of participatory handicrafts by humanitarian donors and supporters, thus informing fundraising, membership through consumption and the communication of sufferings. This call for papers was answered by historians working in the fields of social and labour history, histories of humanitarianism, textile history, and the history of development (both Soviet and Western models). Sessions for the two-day workshop were organised as follows:

\section{Session 1: The Politics and Practices of Arts and Crafts in the Late-Nineteenth and Early-Twentieth Centuries}

Janice Helland, Queen's University, Canada

'Work of Hands': Philanthropy, Craft, and Fair Trade in Britain and Ireland, 1885-1910

Helen Dampier, Leeds Beckett University, and Rebecca Gill, University of Huddersfield Emily Hobhouse and the Boer Home Industries

Bertrand Taithe, Humanitarian and Conflict Response Institute Missionaries and Arts and Crafts - representations of Africa, 1920-1930

\section{Session 2: Handicrafts and Humanitarian Dreams}

Wendy Wiertz, KU Leuven

Belgian Lace as a Humanitarian Product During the First World War

David Hopkin, Hertford College, University of Oxford

Belgian War Lace and the dream of an internationally coordinated handmade lace industry

Nicolette Makovicky, Oxford School of Global and Area Studies

Crafting Communist Paternalism: The Voices of Lacemakers in Koniaków, Poland (1947-1989)

Elizaveta Berezina, Central European University

Handicraft Humanitarianism under the Soviets: Inventing New Crafts for People's Salvation

\section{Session 3: Crafting Values: War, Genocide and Re-Construction}

Jaclyn Granick, Cardiff University

Handicraft as Answer to the Jewish Question: Jewish Youth Productivization after the Great War

Sian Roberts, University of Birmingham

Threads of Friendship: Quaker women relief workers and 'Peasant Handicrafts' in Russia and Poland, 1916-1939 
Jo Laycock, University of Manchester, and Stéphanie Prévost, Paris Diderot University, France Unpicking 'National Tradition': Needlework and the International Response to the Armenian Genocide

Maria Småberg, Lund University Swedish Humanitarian Work among Armenian Refugees in Thessaloniki, 1923-1947

\section{Session 4: Handicrafts, Commerce and Fairtrade in the Twentieth Century}

Adam Millar, University of Leicester

From Hong Kong to Huddersfield: Elizabeth Wilson, Chinese Refugee Handicrafts, and Benevolent Consumerism in the UK, c.1959

Chrissie Webb, Bodleian Library, University of Oxford

'Helping by Selling' - Oxfam and Handicrafts

Carol Wills, Oxford Fair Trade Coalition

Oxfam Bridge and the development of the World Fair Trade Organisation

Jessica Field, O.P. Jindal Global University

A Fundraising Empire? Helping Hand Gift Shops in South Africa, 1971-1978

The participatory craft event took the form of a textile workshop. It presented an insight into $\mathrm{Ni}$ En More humanitarian clothing collection (www.nienmore.com) through participation in the process of naturally dyeing fabric, leaving an individual identity in the cloth using dye matter sourced from the locality. Delegates from the conference participated in this programmed event, as a nod towards experiencing processes of making a humanitarian textile first hand. It provided a moment to absorb and respond to the physicality of material; to strengthen a connection to the supporting exhibition through the real-life demonstration of textiles as a tool for the communication of a humanitarian initiative; and to consider the possibilities it may offer in the academic domain.

The accompanying exhibition displayed historic pieces from the Boer tweed collection and Hudfam alongside contemporary works by Susie Vickery, Lynn Setterington, Claire Wellesley Smith, artist duo arthur+martha and Dilara Changis. Some of the works questioned ideas about the capacity for textiles to alter the way that individuals may engage emotionally with different circumstances, particularly during periods of conflict and displacement. Others offered alternatives to poverty, substituting a beleaguered relationship to the status quo with reassembled structures of peoples' lives through creative craft-based enterprise. Additional artefacts by A. N. Crafts (a small grassroots organisation that has developed out of independent relief work undertaken during the 2015 earthquake in Nepal which left many villages and towns devastated), the Shika Fashion Label (a social enterprise supporting a group of women who make clothing and accessories in a small workshop in the deprived area of Sinone in Arusha in Northern Tanzania to sell in the UK) and Homeless Beanies (HBUK) (a Bradford charity that provides practical support to those who need it most across the city) further supported an inspiring story and powerful statements of creative resilience that embrace the difficulties and joys of crafting in different places all over the world.

During the workshop, a two-pronged discussion began to take place, formally in the Q\&A following the workshop sessions, and informally during the breaks and during participation in the craft event. In the more formal discussion, the conversation revolved around history (the limits of archival knowledge and textual representations, the possibility of identifying continuities and themes, and the difficulty of discerning the voices of historical craft workers in the archive) and heritage (the present day uses and inventions of narratives and objects from the past to tell stories about the present and convey 
ideas of continuity, authenticity, community and identity). In general, participants observed the continuities of personnel, organisational ideals and practices, fundraising and merchandising strategies, and moral geographies shared by many of the historical case studies under discussion, as well as the difficulties of recouping the agency and creative expression of humanitarian subjects in these contexts. In terms of advocacy work, continuities between the historical case studies and present-day humanitarian handicraft projects were noted in relation to how values and ethics become embodied in cloth, in how and why traditions of the humanitarian handcrafted aesthetic and practice exist, and in the significant prevalence of the workshop model as a site of humanitarian production. In the informal discussion, participants began to tentatively and spontaneously pose questions and offer reflections on observable, but often unacknowledged, aesthetic continuities of form and style, as well as their personal histories of wearing and owning humanitarian handicraft. They also reflected on the informal and formal transmission of skill, of bodily (often gendered) comportment and affect, of the nature of sociability in a workshop setting, of the learnt behaviour of voice and gesture in craft making, and of the emotions we bring to bear on craft and on the experience of making. When engaging with the displays and taking part in the craft events, participants were also drawn repeatedly to ask about the specific value we place on the handmade object in these contexts, and how humanitarian handicrafts are labelled and marketed.

During the workshop, we became aware of a number of creative tensions and points where communication across disciplines, though always curious and respectful, nevertheless lacked a shared frame of reference. Of these creative tensions a number can be identified: Did the papers and the exhibits exist in juxtaposition, in parallel or continuity? Was there value in the opportunity for craft production by historians, and if so what insights did it glean? Did the historical narrative of continuity (particularly of the role of colonialism and ethnic nationalism) overly determine our response to the current-day objects on display? Was this to the detriment of an appreciation of the specific context of their production, particularly their role in contemporary feminist movements and the artistic expression of their creators? In participating in the craft events, were we merely performing the roles of humanitarian handicraft workers, and was this ethically acceptable? These initial observations and these creative tensions pushed us to begin to reflect and read more critically both on the possibilities and limitations of participating in craft for historians of humanitarianism and on the insights afforded by historical precedent for the contemporary ethics of humanitarian craft work. The rest of this paper constitutes our deepening reflection - by no means complete - upon these forms of knowledge exchange.

One starting point for this reflection is Minoo Moallem's study of Persian carpets, and we seek to respond to her imperative to address how certain textile commodities were - and are - made 'into a spectacle, in addition to turning the labour that produces the commodity into a spectacle - one that has the potential to both conceal and reveal' (Moallem, 2018). We thus wish to identify how textiles and their makers featured in a variety of humanitarian schemes, usually aimed at one or more of the following: securing safe employment (typically for girls and women); preserving or creating cultural heritage, including forms of ethnic culture; improving labour conditions and workers' social and economic position; engaging in gender-based advocacy and awareness raising; providing 'moral' occupation and therapeutics. Often these textiles were produced for sale or exchange on the open or charity market, or for collection and display. In some contexts, the social, aesthetic or market value of the textile might be called upon to bestow tangible or intangible value on its maker. In other contexts, the value of the making process (the 'moral' circumstances of production) might, at the same time as concealing other circumstances of its production, bestow value on the textile. In both cases, the textile is turned into a humanitarian commodity. These were affective as well as social relationships, pivoting on both ethical commitment and sensory and emotional connections. For these relationships to occur, labelling is crucial, for the textile must exist in dialogue with a narrative of its production. In our postworkshop discussion, we thus revisited photographs from the workshop to look closely at labels. 


\section{REFLECTING ON CRAFT IN ACTION: MAKING HUMANITARIAN HANDICRAFTS}

At the Humanitarian Handicrafts event, participant workshop-based sessions brought an open space of possibility in the making process facilitated by the international artist Lise Bjørne Linnert. Artists and human rights activists from Norway, United States and Mexico have set up a small-scale sewing studio in a safe part of Ciudad Juárez where local women coming from vulnerable and marginalised areas in the city produce handmade, one-of-a-kind garments called Ni En More. The garments come with a story tag and a protest badge and can be worn as a protest against the abuse of women worldwide. All the clothing is naturally stained using flowers from the locality and growing in the Chihuahua district in Mexico, with many local flower shops providing their wilting flowers to the Ni En More Studio.

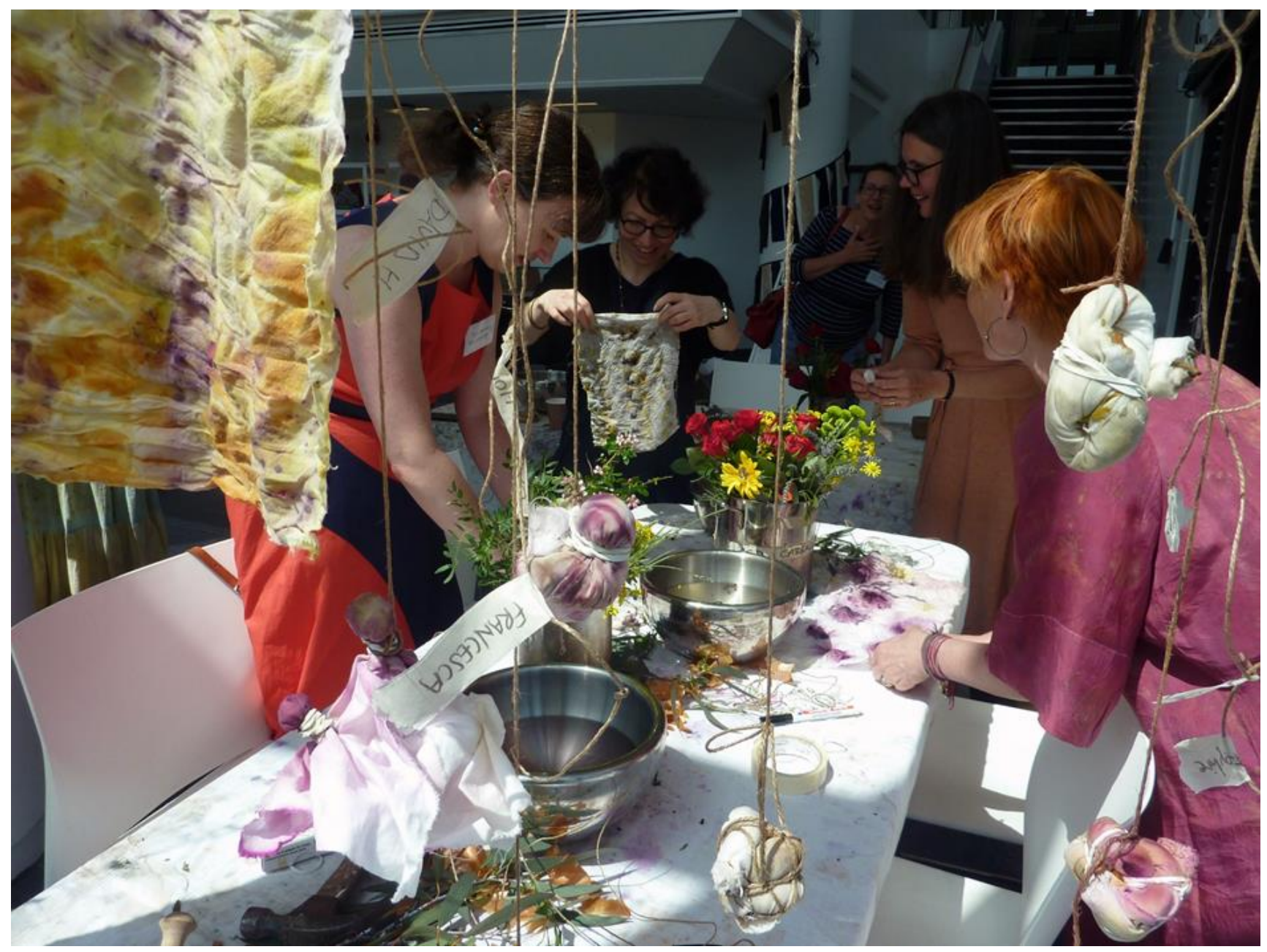

FIGURE 1: View of Ni En More staining workshop instructed by Lise Bjørne Linnert part of the Humanitarian Handicrafts exhibition at the Holocaust Education and Exhibition Centre, University of Huddersfield 27 June - 4 July 2019 . (Image courtesy of Claire Barber)

In his essay 'On Weaving a Basket', Tim Ingold points out that:

The more objects are removed from the context of life-activity in which they are produced and used the more they appear as static objects of disinterested contemplation (as in museums and galleries) the more, too, the process disappears or is hidden behind the product, the finished object. (Ingold, 2009)

Taking stock of Ingold's commentary, we invited conference delegates to make an excursion from the lecture theatre and to visit the artist Lise Bjørne Linnert to take part in some of the making processes employed in the Nie En More collection using natural dyes sourced from the Huddersfield canal towpath 
to hand-stitch protest badges. This was an attempt to shed light on the fashion collection beyond its perceivable static visual structure as presented on a website or within an exhibition. This activity is led by a conviction of the importance of approaches that cannot be experienced intellectually, and to challenge assertions that an involvement in craft-making process for historians are inconsequential. We may now start to appreciate the humanitarian artefact as an open-ended site through which to join in as an observer and active participant. This is not a customary approach for historians.

\section{RE-THINKING HISTORIES OF HUMANITARIANISM}

Historians working from archival evidence and scant remains of artisanal production are limited by their evidence to producing a discourse often focusing on the humanitarian sociodicy (Fassin, 2011) and broader political intents of humanitarian initiatives in setting up artisanal, craft or art workshops. They soon face the limitations of their methodology when they seek to understand the physical dimensions of the labour involved, and the affect and aesthetic of what Malkki (2015) decries are often called 'mere' textiles. Most existing studies are limited in scope and tend to ignore the existence of a long humanitarian tradition with a strong material genealogy which is fragmented and ill represented in institutional archives.

These issues were in evidence across the papers of the workshop, which showed well the range of questions historians raised and to which they could only give partial answers. The few humanitarian handicrafts in museum collections often lack context or participant narratives and the voice of the creators and consumers, and do not enable historians to fully comprehend their origins or multiplicity of meaning and purpose. A participatory crafting workshop enabled a different range of conversations to take place which emphasized the complexity of the production processes but also their sociability. Lise Bjørne Linnert's intervention in particular highlighted the considerable work done by stories of origins, of product tags and labelling in providing the humanitarian narrative within which the object is given meaning and which may condition our sensory and affective responses and give a particular quality of touch to the hand-made product in this context (Hill, 2012).

The tag addresses the way that the consumer is taught, sold and presented with an artefact that addresses questions of what the item is for. It is not assumed that the consumer will know; it is explained and presented in plain terms: This is a truly unique piece - the only one in existence. Please treat it gently and handle with care. Through the medium of craft, the tag guides an encounter with a modest, inimitable and unpretentious garment stained in muted colours with potential to provide a measure of equilibrium to the more overt visual stimulation upon which fashion is deemed to depend. Perhaps the value of the tag is to enable a conception for cloth to connect with issues and circumstances of its making that we may otherwise have trouble identifying with. The tag descriptor continues: Natural dyes respond best to hand-wash and PH neutral soap in cool water. Press with a steam iron. Keep the garment away from excessive sunlight when you are not wearing it, direct sunlight might bleach it. Treat it this way, and you unique NI EN MORE item will last a long time. Attention is now focused on the responsibility of the consumer to care for the handcrafted textile. The consumer is not unaware of the frailties of the women's lives that created the garment (documentaries are presented on the $\mathrm{Ni}$ En More website and were viewable in the Humanitarian Handicrafts exhibition) such that an emotional connection with the maker unfolds each time the item is washed and ironed helping to imbue the cloth with a particular 'moral atmosphere' (De Botton \& Armstrong, 2015).

Ultimately the tag pays attention to the detail of the dyes used: This item has been dyed and printed with Mayan Pigment, flower compost and rust. Here it is, a sincere homage to the natural dye matter used to create the colours of the garment. Plant based colours bring a complexity of tones and shades that are a reflection of the place where they were sourced. We may have paid little attention to this process of procuring colour before, what is at stake is an aesthetic quality that is less flat and uniform than the more resilient commercial dyes produced by its artificial counterparts, exposing an awareness of the fragility of textile-based expression underlying the Ni En More project. The subtle depth of tones and shades of the fibre is reflected back to us in a display case in the centre of the Humanitarian Handicrafts exhibition containing two tweed samples of cloth created over 100-years earlier; initiated by Emily Hobhouse it is a project that employed naturally dyed hand spun and woven 
textiles to assist in moral and social uplift of (white) Boer women in rural South Africa at a time of emerging cultural nationalism. Ni En More can inform historical reconsiderations of handicraft, in no small part due to the gestures of touch, the ephemera of a label or marketing sticker, the power of affective relationships that can occur in engaging with the textile object, none of which is captured in an archive. This can afford new insight into the tangible and intangible relationships of production and consumption, gendered performance and sociability, and the qualities attached to hand-crafted items in the humanitarian imagination, and the potential effects of these objects as sociocultural participants in their own right (Auslander, 2018).

Each recipient of a garment will find their own direction through the project; but the tag offers a route map. For some, imperfections in the clothing may teach us that deficiencies in our vantage points need not be hidden; we know we cannot answer the question of a satiated fast-fashion industry, but if we carefully launder a garment with PH neutral soap we become attentive to the aesthetic value of a fabric that only remains beautiful if we offer the time to care for it. For some of us we conceded to the project through our own participation in a natural dye workshop with the artist Lise Bjørne Linnert, an opportune and visceral reminder of the embodied experience encoded in a piece of textile created by hand.

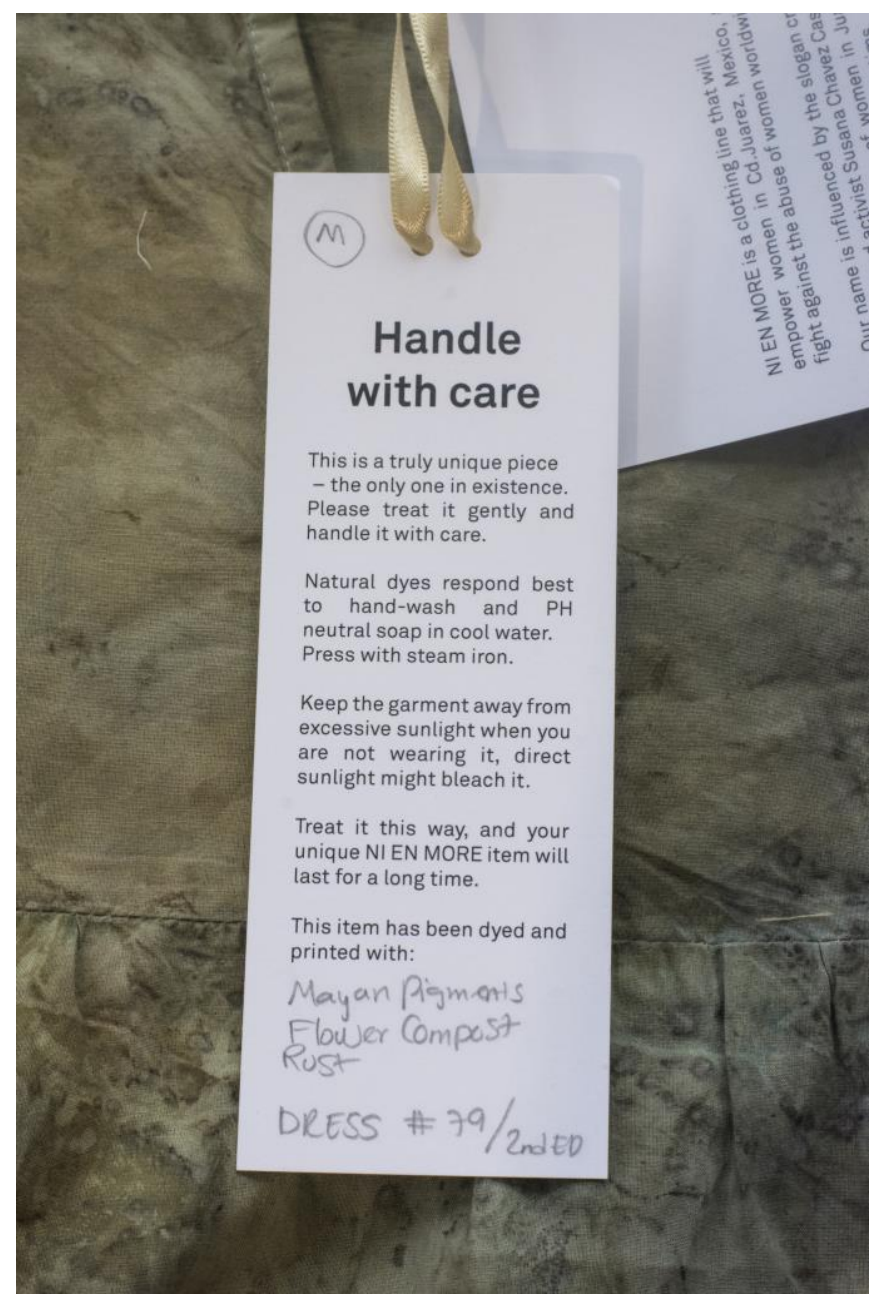

FIGURE 2: Photograph of a Ni En More dress label by Lise Bjørne Linnert part of the Humanitarian Handicrafts exhibition at the Holocaust Education and Exhibition Centre, University of Huddersfield 27 June - 4 July 2019. (Image courtesy of Alex Jade Webb)

Of course, whether this was a process of mimicking or of authentically making humanitarian handicrafts invites further reflection. If one could argue that historians were 'pretending' to make textiles and were 
thus engaged in a re-enactment process rather than a critical examination, then it is also necessary to inquire further into this question of authenticity and human connection which runs through the historical production and consumption of humanitarian handicrafts - and ask what role such objects and making processes have in the humanitarian imagination. This in turn forces us to reflect upon some of the enduring aesthetics and narratives associated with humanitarian handicrafts and read the history of humanitarianism through senses and objects as well as texts. This suggests the benefits of an affective engagement with production, connecting 'emotions' in the making of artefacts which historians (Steedman, 1998) have often commented on as being absent from 'normal' historical accounts, and providing a point of dialogue for historians of humanitarianism, curators, archivists, and contemporary craft practitioners.

The fusion of ethics and aesthetics in the handmade humanitarian textile - the emphasis on authenticity, 'natural' production processes such as the use of plant dye, and traditional skill - invites particular reflection. Do affective responses alter as a result of changing ethical positions? How are ethics aestheticized, labelled and narrated? Why is the handcrafted aesthetic so durable, and what does it signal and allude to? How do humanitarian handicrafts encode a relationship between consumer and producer, or between buyer and cause, at any one point and place? For the field of humanitarian history more usually concerned with tracing the origins of modern professional and scientific practices or legal norms it is important to be reminded of this emphasis on the handcrafted and artisanal and on the value placed on 'traditional' handwork and on their aesthetic implications. The humanitarian or development workshop embodied a span of political options ranging from a desire to preserve or restore gender roles, 'develop' a reformed rural idyll, or conserve imperial, national or missionary relationships. In view of the recent critique of the inherent conservatism of humanitarianism in a colonial context (Lester, 2014), the workshop and the ideals of craft could be seen to be imbued with a politics of nostalgia. Yet as historians of humanitarianism have called for greater attention to the beneficiary perspective (Baughan, 2018), a focus on humanitarian handicraft production also allows us to consider the beneficiary as maker with a particular kind of agency. This may contest the intended aims of a workshop set-up. Hand-produced textile work involves sociability, transmission of skill, the production of knowledge including sensory and affective knowledge, folklore processes, relationship formation, and creativity (textiles are a hylomorphic model of form creation which involve agency in making) (Arantes, 2020). Taking this focus alerts us to the place of the workshop as a perennial site of humanitarian action, and of the split ethics of gendered humanitarian labour and education in humanitarian textile projects.

\section{THE STITCH IN TIME: TOWARDS INTERDISCIPLINARITY}

The title of our paper emphasises materiality and practice as our medium of exchange and dialogue. We have offered some preliminary reflections on how embodied knowledge and command of process can inform a 'participatory history' that encourages historians to attend to process and material object, and craft practitioners to engage artistically and theoretically with the historical and aesthetic referents within which their work exists. Our point is not to denigrate or offer facile comparision, but rather to work together with 'critical respect' across disciplines to better engage both communities in a critical reading of narrative and process. We wish to enable deeper reflection on the cultural work done by the production of 'humanitarian' crafts and their labelling and to consider the potential of historical methods and critical inquiry for a contemporary ethics of care which considers the implication of these genealogies and aesthetic continuities in textile projects, particularly for women. The craft workshop has a long tradition in humanitarian handicraft projects: it is the site both of restrictive labour practices for women and of feminist grassroots activism, inviting consideration of the precise historical, social and economic relationships within which the spectacle of the humanitarian commodity is produced. Meanwhile, for the historian, more usually occupied with tracing ideals in written charity appeals, the ability to engage with the material craft object allows for greater consideration of how the ethics of care in the past was embodied in and experienced through material objects, providing insight into unspoken or unwritten legacies (potentially still in evidence), and allowing for cross-cultural humanitarian exchanges to be better understood. Participant observation through handiwork reveals the ways that that textile craft is a form of embodied knowledge, is bound by bodily conventions and gendered 
sociability and performance, very rarely documented of course, but suggestive of the possibilities for new historical perspectives on humanitarian enterprises and their absorption, adaptation, and even their possible subversion (Parker, 2012). 


\section{REFERENCES}

Arantes, L. (2020). Unravelling Knitting: Form Creation, Relationality, and the Temporality of Materials. Journal of American Folklore, 133(528), 193-204. https://doi.org/10.5406/jamerfolk.133.528.0193

Auslander, L. \& (2018). Objects of War: The Material Culture of Conflict and Displacement. Cornell University Press.

Baughan, E., Davey, E., Everill, B., O'Sullivan, K., \& Sasson, T. (2018). History and Humanitarianism: A Conversation. Past and Present, 241, e1 - e38. https://doi.org/10.1093/pastj/gty040

De Botton, A., \& Armstrong, J. (2015). Art as Therapy. Phaidon Press.

Fassin, D. (2011). Humanitarian Reason: A Moral History of the Present. University of California Press. https://doi.org/10.1525/9780520950481

Hill, J. (2012). Sense and Sensibility. In Jessica Hemmings (Ed.), The Textile Reader (pp. 37 - 43). Berg.

Ingold, T. (2009). On Weaving a Basket. In F. Candlin \& R. Guins (Eds.), The Object Reader (pp. 339 - 348). Routledge.

Lester, A. (2014). Colonization and the Origins of Humanitarian Governance. Cambridge University Press. https://doi.org/10.1017/CBO9781139022026

Malkki, L. (2015). The Need to Help: The Domestic Arts of International Humanitarianism. Duke University Press. https://doi.org/10.1215/9780822375364

Moallem, M. (2018). Persian Carpets: The Nation as a Transnational Commodity. Routledge. https://doi.org/10.4324/9781315266435

Ni En More. https://www.lisebjorne.com/ni-en-more/

Parker, R. (2012). The Subversive Stitch: Embroidery and the Making of the Feminine. I.B.Tauris.

Steedman, S. (1998). What a rag rug means. Journal of Material Culture, 3(3), 259-281. https://doi.org/10.1177\%2F135918359800300301 